\title{
Kajian Tipe dan Komponen Pasang Surut Di Pantai Sigandu Kabupaten Batang
}

\author{
Taufiq Hidayat ${ }^{1}$, Warsito Atmodjo $^{1}$, Hariyadi ${ }^{1}$, Heriyoso Setyono ${ }^{1}$, Aris Ismanto ${ }^{1}$, Agus Anugroho Dwi \\ Suryoputro ${ }^{1}$ \\ ${ }^{1}$ Departemen Oseanografi, Fakultas Perikanan dan Ilmu Kelautan, Universitas Diponegoro \\ Jl. Prof. Sudarto, SH Tembalang Tlp. / Fax. (024)7474698 Semarang 50275 \\ Email corresponding author: taufiq080595@gmail.com
}

\begin{abstract}
Abstrak
Pasang surut adalah peristiwa alam tentang naik turunnya permukaan air laut yang terjadi secara berulangulang dan teratur karena adanya gaya gravitasi benda - benda di langit terutama bulan dan matahari terhadap massa air laut di bumi. Kajian tipe dan komponen pasang surut dapat diketahui dengan cara perhitungan mengenai data amplitudo dan beda fase yang merupakan komponen pasang surut. Penelitian ini bertujuan untuk mengetahui tipe dan komponen pasang surut dengan metode Admiralty dan meramalkan pasang surut dengan menggunakan software World Tides, Mike21 selama 3 tahun (2017-2019). Penelitian ini dilaksanakan pada tanggal 15 Februari 2017 - 01 Maret 2017 di Perairan Sigandu Kabupaten Batang Jawa Tengah. Data yang digunakan dalam penelitian ini adalah data pasang surut pengamatan pada lokasi penelitian dan koordinat lokasi penelitian. Hasil penelitian dengan mengunakan metode Admiralty menunjukan bahwa tipe pasang surut di Perairan Sigandu Kabupaten Batang Jawa Tengah adalah tipe pasang surut condong harian tunggal dengan nilai Formzahl sebesar 1,88. Nilai Mean Sea Level (MSL) sebesar $78 \mathrm{~cm}$, nilai High Water Level (HWL) sebesar $108 \mathrm{~cm}$, dan nilai Low Water Level sebesar $50 \mathrm{~cm}$.
\end{abstract}

Kata Kunci: Pasang Surut, Admiralty, Mike21, World Tides, Pantai Sigandu

\begin{abstract}
Tidal is a natural events about the ups and downs are natural events about the ups and downs of sea levels that occur repeatedly and regularly due to the gravitational force of objects in the sky, especially the moon and sun against the sea water mass on earth. Study of tidal types and components are known by calculating data amplitude and phase difference which is tidal component. This study aims to determine the characteristics of the tides with Admiralty method and forecast the ups and downs by using WorldTides software, Mike21 for 3 years (2017-2019). The research was conducted on February 15 $5^{\text {th }}, 2017$ - March $1^{\text {st }}, 2017$ in Sigandu Waters, Central Java Batang Regency. Data used in this research is tidal observation data at research location and coordinate of research location. The results of research using Admiralty method showed that the type of tides in Sigandu Waters of Central Java Batang Regency is a single daily tidal type of tidal with a value of Formzahl of 1.88. Mean Sea Level (MSL) of $78 \mathrm{~cm}$, High Water Level (HWL) of $108 \mathrm{~cm}$, and Low Water Level of $50 \mathrm{~cm}$.
\end{abstract}

Keywords: Tidal, Admiralty, Mike21, WorldTides, Sigandu Beach

\section{PENDAHULUAN}

Perairan Sigandu terletak di Desa Klidang Lor, Kecamatan Batang, Kabupaten Batang. Perairan Sigandu terletak diantara $6^{\circ} 51^{\prime} 46^{\prime \prime}-7^{\circ} 11^{\prime} 47^{\prime \prime}$ LS dan $109^{\circ} 40^{\prime} 19^{\prime \prime}$ - $110^{\circ} 03^{\prime} 06^{\prime \prime}$ BT di pantai utara Jawa Tengah, masyarakat yang tinggal di Perairan Sigandu memiliki mata pencaharian sebagai nelayan. Perairan Sigandu dipilih sebagai daerah penelitian karena banyaknya jumlah kapal sebanyak 1.290 unit yang bersandar di Perairan Sigandu. Dalam hal ini fungsi pasang surut dalam bidang oseanografi dibutuhkan, khususnya untuk melihat karakteristik dan kenaikan muka air laut di Perairan Sigandu masih cukup aman atau perlu dilakukan pengembangan pelabuhan lebih lanjut sebagai tempat sandar kapal, dimana hal tersebut bermanfaat bagi banyak pihak terutama nelayan dan juga pemegang keputusan dalam mengelola perencanaan pengembangan kawasan pelabuhan. 
Tujuan penelitian ini untuk mengetahuiMengetahui tipe pasang surut di Perairan Sigandu, Kabupaten Batang Jawa Tengah dan Meramalkan pasang surut selama 3 tahun (Tahun 2017-2019) untuk mengetahui nilai MSL (Mean Sea Level), HWL (High Water Level) dan LWL (Low Water Level).

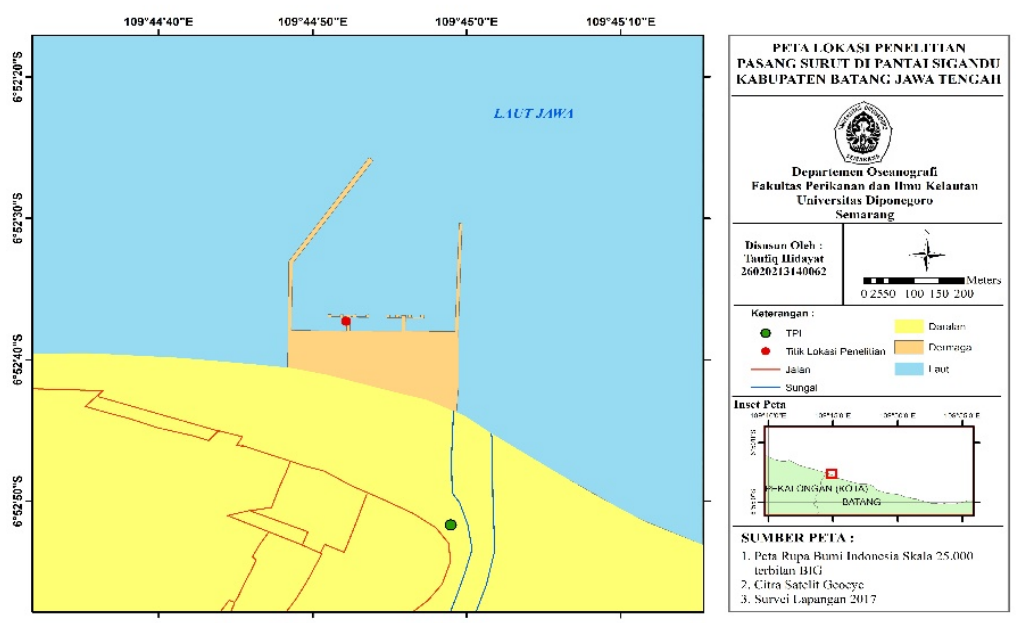

Gambar 1. Lokasi Penelitian

\section{MATERI DAN METODE}

Materi yang digunakan pada penelitian ini meliputi data utama dan data pendukung. Data utama yang digunakan adalah hasil pengukuran elevasi pasang surut muka air laut di lapangan yang dilakukan di Perairan Sigandu Desa Klidang Lor, Kecamatan Batang, Kabupaten Batang dengan periode pengamatan selama 15 hari dan interval pengukuran 1 jam. Data pendukung berupa data data pasang surut dari instansi (Badan Meteorologi, Klimatologi dan Geofisika) BMKG Semarang.

Pada penelitian ini menggunakan metode kuantitatif. Metode kuantitatif merupakan metode yang menggunakan data berupa angka dan dianalisa secara statistik atau menggunakan model (Sugiyono, 2011).

\section{Metode Pengambilan Data}

Karena pada setiap perairan memiliki karakteristik dan tipe pasang surut yang berbeda maka pengambilan data tinggi elevasi muka air laut pada skala waktu 1 jam maka akan menghasilkan komponen - komponen pasang surut yang akan menggambarkan tipe pasang surut pada perairan tersebut. Pengamatan dilakukan dengan cara membaca skala dengan ketelitian $1 \mathrm{~cm}$ yang tertera pada palem pasut yang terendam oleh air laut setiap satu jam sekali, selama 15 hari. Proses analisa harmonik pasang surut diawali dengan merubah terlebih dahulu data pasang surut ke dalam satuan meter atau feet, kemudian diurutkan berdasarkan urutan waktu pengamatan menggunakan perangkat lunak Microsoft Excel. Setelah itu proses selanjutnya adalah memasukan data pasang surut dan koordinat titik pengamatan kedalam program Mike 21 kemudian menggunakan program tide prediction of height untuk peramalan pasang surutnya dan akan didapatkan hasil dari peramalan tersebut beserta komponen - komponennya.

\section{Metode Pengolahan Data}

Hasil pengolahan data pasang surut dengan metode Admiralty adalah komponen harmonik pasang surut. Berdasarkan komponen harmonik pasang surut diperoleh nilai evelasi muka air laut (MSL, HWL dan LWL). Tahap pengolahan data dimulai dengan pengolahan data pasang surut menggunakan metode Admiralty untuk menentukan tiap - tiap komponen pasang surut. Data pasang surut yang sudah diolah dan koordinat lokasi penelitian kemudian dijadikan sebagai inputan dari model peramalan pasang surut menggunakan beberapa metode yaitu: World Tides dan Mike21. Hasil dari pemodelan berupa data elevasi pasang surut dalam bentuk deret waktu (time series) dari elevasi muka air pasang surut terhadap MSL (Mean Sea Level) Perairan Sigandu Kabupaten Batang Jawa Tengah. 


\section{HASIL DAN PEMBAHASAN}

Pengolahan data pasang surut bulan Februari - Maret tahun 2017 dilakukan dengan menggunakan metode Admiralty selama 15 hari dan didapat konstanta harmonik pasang surut, sebagaimana disajikan pada tabel 1.

Tabel 1. Komponen Harmonik Pasang Surut Hasil Perhitungan menggunakan Metode Admiralty di Perairan

\begin{tabular}{|c|c|c|c|c|c|c|c|c|c|c|}
\hline & \multicolumn{10}{|c|}{ Sigandu pada 15 Februari-01 Maret 2017} \\
\hline & $\mathrm{S}_{0}$ & $\mathrm{M}_{2}$ & $\mathrm{~S}_{2}$ & $\mathrm{~N}_{2}$ & $\mathrm{~K}_{1}$ & $\mathrm{O}_{1}$ & $\mathrm{M}_{4}$ & $\mathrm{MS}_{4}$ & $\mathrm{~K}_{2}$ & $\mathrm{P}_{1}$ \\
\hline $\begin{array}{l}\mathrm{A} \\
\mathrm{cm}\end{array}$ & 78 & 6 & 4 & 2 & 19 & 1 & 0 & 0 & 1 & 6 \\
\hline $\mathrm{g}^{\circ}$ & & 333 & 190 & 229 & 207 & 110 & 352 & 192 & 190 & 207 \\
\hline
\end{tabular}

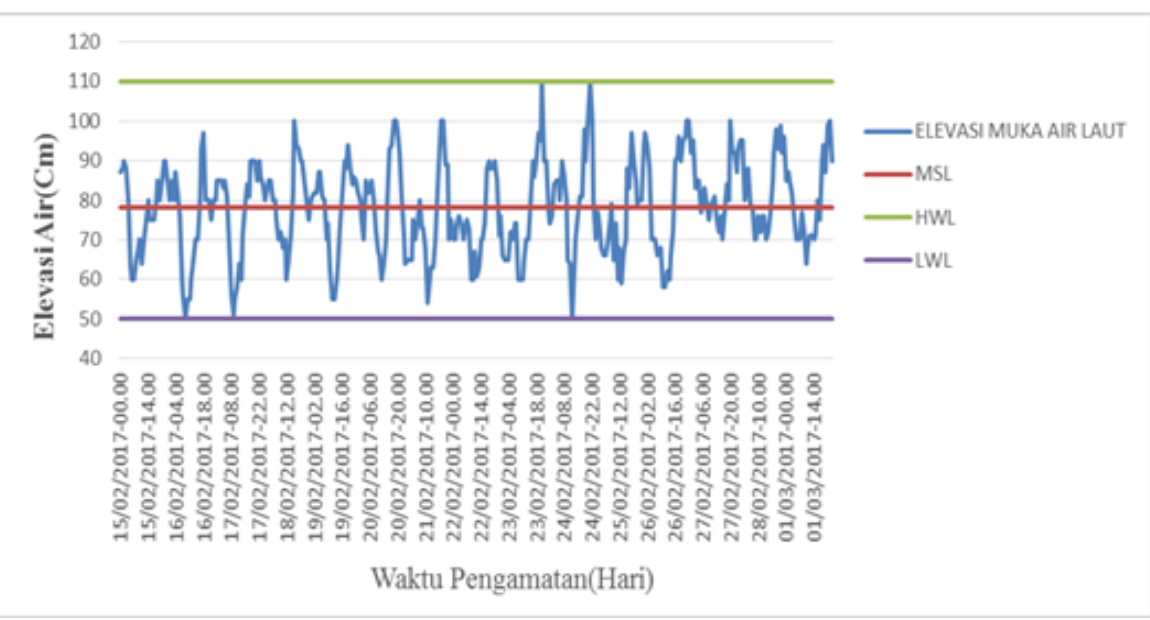

Gambar 2.Grafik Pasang Surut Perairan Perairan Sigandu pada 15 Februari -01 Maret2017

Pengolahan data pasang surut menggunakan metode Admiralty selain menghasilkan beberapa komponen pasang surut juga dapat digunakan untuk mencari nilai Mean Sea Level (MSL), High Water Level (HWL), Low Water Level (LWL). Sehingga diperoleh nilai MSL sebesar $78 \mathrm{~cm}$, nilai HWL sebesar $110 \mathrm{~cm}$, dan nilai LWL sebesar $50 \mathrm{~cm}$. Peramalan pasang surut dilakukan dengan menggunakan program Mike21 untuk 3 tahun kedepan yaitu mulai dari tahun 2017 sampai dengan tahun 2019. Peramalan dilakukan dengan memasukkan koordinat lokasi penelitian kemudian menentukan waktu awal dan waktu akhir peramalan pasang surut berupa tahun, bulan, tanggal, jam, menit, dan interval waktu pengambilan data pada standar GMT. Berdasarkan plotting antara data pengamatan dan data peramalan World Tides diperoleh nilai kebenaran sebesar 92,48 \% dan Mike21 92,40. Perbandingan data pasut lapangan dan tiap metode tersaji pada Gambar 3 dan Gambar 4. 


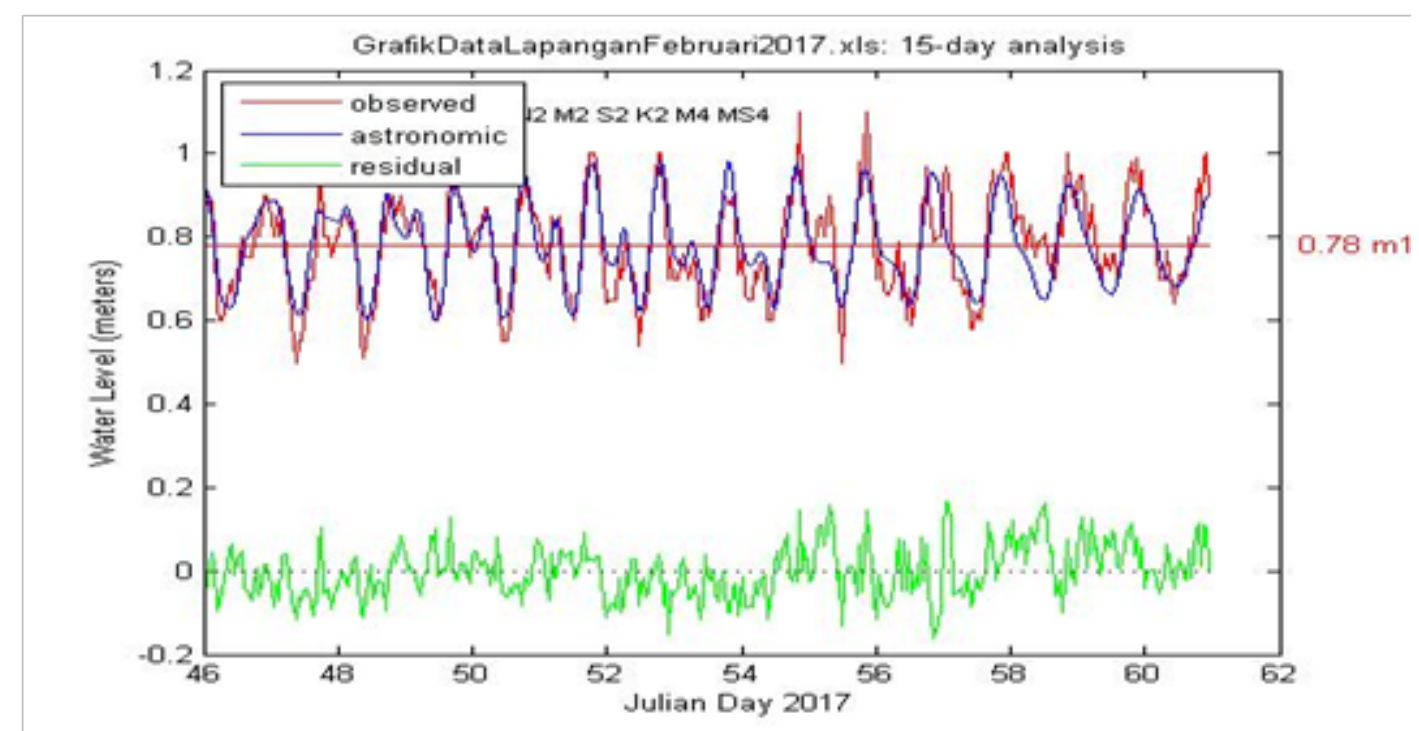

Gambar 3. Grafik verifikasi elevasi muka air lapangan dengan software World Tides

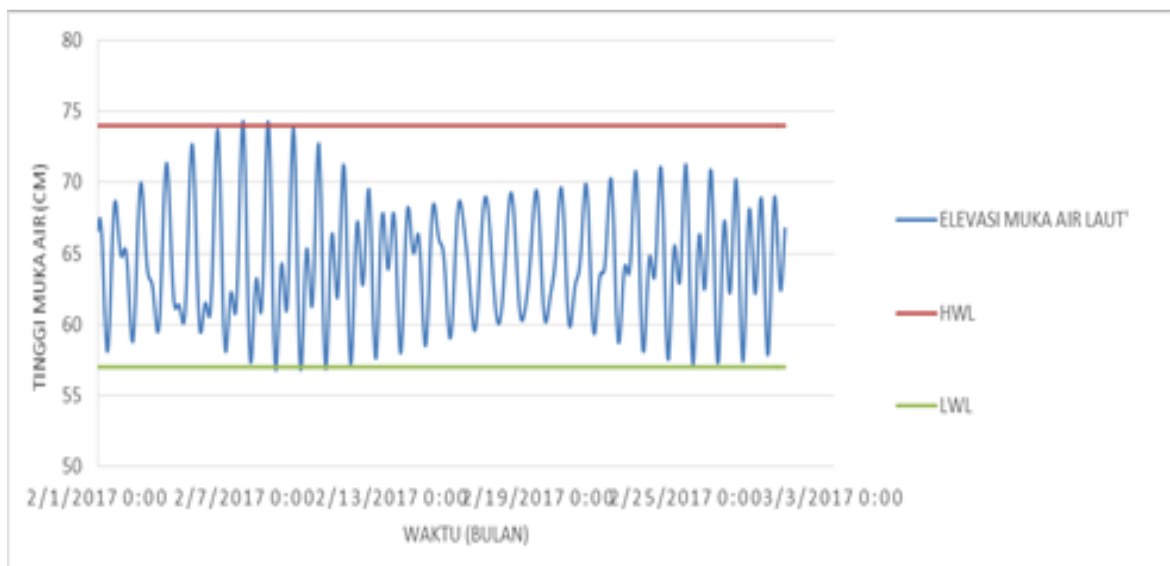

Gambar 4. Grafik verifikasi elevasi muka air lapangan dengan software Mike21

Berdasarkan hasil yang diperoleh dari pengolahan metode Admiralty data pasang surut lapangan menunjukan bahwa nilai K1 yang merupakan pasang surut diurnal yang dipengaruhi oleh deklinasi Bulan dan Matahari adalah nilai yang paling mendominasi dengan nilai sebesar $19 \mathrm{~cm}$, sedangkan data pasang surut yang diperoleh dari (Badan Meteorologi, Klimatologi dan Geofisika) BMKG Semarang menunjukan bahwa nilai K1 sebesar $27 \mathrm{~cm}$.

Untuk komponen lainnya seperti $\mathrm{M}_{2}, \mathrm{~S}_{2}, \mathrm{~N}_{2}, \mathrm{~K}_{2}$ yang merupakan komponen pembangkit pasang surut ganda atau semi diurnal nilainya relatif kecil dengan nilai $\mathrm{M}_{2}$ sebesar $6 \mathrm{~cm}, \mathrm{~S}_{2}$ sebesar $4 \mathrm{~cm}, \mathrm{~N}_{2}$ sebesar $2 \mathrm{~cm}$, sedangkan data yang diperoleh dari BMKG menunjukkan nilai yang tidak jauh berbeda dengan hasil pengamatan selama di lokasi penelitian yaitu dengan nilai $\mathrm{M}_{2}$ sebesar $11 \mathrm{~cm}, \mathrm{~S}_{2}$ sebesar $6 \mathrm{~cm}, \mathrm{~N}_{2}$ sebesar $4 \mathrm{~cm}$. Sedangkan untuk komponen $\mathrm{M}_{4}$ dan $\mathrm{MS}_{4}$ memiliki nilai yang paling kecil dari yang lainnya dengan nilai sebesar 0 untuk $\mathrm{M}_{4}$ dan 0 untuk $\mathrm{MS}_{4}$, Nilai tersebut juga tidak jauh berbeda dengan hasil dari BMKG yang menunjukan nilai $\mathrm{M}_{4}$ Sebesar $1 \mathrm{~cm}$ dan $\mathrm{MS}_{4} 0 \mathrm{~cm}$. Hal tersebut dapat diartikan bahwa perubahan kedangkalan tidak berpengaruh besar terhadap kondisi pasang surut di Perairan Sigandu. $\mathrm{M}_{2}$ merupakan komponen pasang surut utama dari Bulan, sedangkan $\mathrm{S}_{2}$ merupakan komponen pasang surut utama dari Matahari (Pinet,1992). Perbandingan dari keduanya memperlihatkan kekuatan pasang surut yang dibangkitkan oleh Matahari dan Bulan di suatu kawasan perairan. Nilai Formzahl yang didapatkan dari pengolahan metode Admiralty memiliki nilai sebesar 1.88 sehingga dapat diketahui bahwa tipe pasang surut Perairan Sigandu adalah tipe pasang surut condong harian tunggal. 
Perairan Sigandu memiliki nilai MSL (Mean Sea Level) sebesar $78 \mathrm{~cm}$, nilai HWL (High Water Level) sebesar $110 \mathrm{~cm}$, dan nilai LWL (Low Water Level) sebesar $50 \mathrm{~cm}$. Dengan data pengamatan yang telah dilakukan selama 15 hari, nilai elevasi muka air laut dapat digunakan sebagai data perhitungan untuk digunakan untuk membantu kegiatan masyarakat disekitar terutama yang berprofesi sebagai nelayan.

\section{KESIMPULAN}

Perairan Sigandu yang terletak di Desa Klidang Lor, Kecamatan Batang, Kabupaten Batang, Jawa Tengah memiliki karakteristik pasang surut campuran condong ke harian tunggal dengan nilai Fromzahl sebesar 1,884. Mean Sea Level (MSL) sebesar $78 \mathrm{~cm}$, Low Water Level (LWL) sebesar $48 \mathrm{~cm}$ dan nilai High Water Level (HWL) sebesar $108 \mathrm{~cm}$. Peramalan Pasang Surut menggunakan metode Mike21 dan World Tides setiap tahun nya berbeda, hal ini dikarenakan komponen pasang surut utama yang disebabkan oleh pengaruh bulan. Hasil Peramalan Pasang Surut menggunakan metode Mike21 selama periode tahun 2017-2019 nilai HWL tertinggi terjadi pada bulan juni Tahun 2018 sebesar $78 \mathrm{~cm}$, sedangkan nilai LWL terendah terjadi pada bulan januari tahun 2019 sebesar $54 \mathrm{~cm}$. Hasil Peramalan Pasang Surut menggunakan World Tides selama periode tahun 2017-2019 nilai HWL tertinggi terjadi pada bulan november tahun 2019 sebesar $141 \mathrm{~cm}$, sedangkan LWL terendah terjadi pada bulan Mei tahun 2018 sebesar $35 \mathrm{~cm}$. Dan untuk hasil MSL tahun 20172019 dengan menggunakan metode Mike21 tertinggi terjadi dibulan Agustus tahun 2017 sebesar $68 \mathrm{~cm}$ dan bulan Juli tahun 2018 sebesar $68 \mathrm{~cm}$, dan MSL tertinggi untuk metode World Tides terjadi di bulan Januari tahun 2018 sebesar $80 \mathrm{~cm}$ dan bulan April tahun 2019 sebesar $80 \mathrm{~cm}$.

\section{DAFTAR PUSTAKA}

Bakti LM. 2010. Kajian Sebaran Potensi Rob Kota Semarang dan Usulan Penanganannya. [Tesis]. Program Pasca Sarjana Universitas Diponegoro, Semarang, $94 \mathrm{hlm}$.

Boon, J.D 2006. WorldTides User Manual. Gloucester, USA, $24 \mathrm{hlm}$.

DHI Water and Environment. 2005. Danish Hydraulic Institute, Denmark, $86 \mathrm{hlm}$.

Fadilah, Suripin dan Dwi P. S. 2014. Menentukkan Tipe Pasang Surut dan Muka Air Rencana Perairan Laut Kabupaten Bengkulu Tengah Menggunakan Metode Admiralty. Maspari Journal. Universitas Diponegoro., 6(1):1-12 hlm.

Musrifin.2011. Analisis Pasang Surut Perairan Muara Sungai Mesjid Dumai. Jurnal Perikanan dan Kelautan. Universitas Riau., 16(1): 48-55.

Nurisman, N., Fauziyah dan Heron S. 2012. Karakteristik Pasang Surut di Alur Pelayaran Sungai Musi Menggunakan Metode Admiralty. Maspari Journal. Ilmu Kelautan FMIPA Universitas Sriwijaya. Indralaya Indonesia., 4(1):111-115.

Nontji, A. 1987 Laut Nusantara. Penerbit Djambatan, Jakarta, 368 hlm.

Ongkosongo dan Suyarso. 1989. Pasang Surut Pusat Penelitian dan Pengembangan Oseanografi-LIPI, Jakarta. $257 \mathrm{hlm}$.

Poerbandono dan Djunarsjah, 2005. Survey Hidrografi. PT. Refika Aditama. Bandung, $166 \mathrm{hlm}$.

Rampengan, R.M. 2013. Amplitudo Konstanta Pasang Surut di Perairan Kota Bitung Sulawesi Utara. Sulawesi Utara. Jurnal Ilmiah Platax, 1(3):118-124 hlm.

Kodoatie, RJ dan Sjarief, R. 2010. Tata Ruang Air. Andi, Yogyakarta, 538 hlm.

Sugiyono, 2011. Metode Penelitian Pendidikan (Pendekatan Kuantitatif Kualitatif dan R \& D). Alfabeta, Bandung, $330 \mathrm{hlm}$.

Triatmodjo, B. 1999. Teknik Pantai. Universitas Gajah Mada. Beta Offset, Yogyakarta. 408 hlm. 